City University of New York (CUNY) CUNY Academic Works

\title{
The role of metalinguistic and socio-cognitive factors in reading skill
}

Hélène Deacon

Dalhousie University

Rebecca Tucker

Dalhousie University

Bradley W. Bergey

CUNY Queens College

\section{How does access to this work benefit you? Let us know!}

More information about this work at: https://academicworks.cuny.edu/qc_pubs/379

Discover additional works at: https://academicworks.cuny.edu

This work is made publicly available by the City University of New York (CUNY).

Contact: AcademicWorks@cuny.edu 



\section{Developmental Perspectives \\ in Written Language and Literacy}

Edited by

Eliane Segers and Paul van den Broek 


\section{Table of contents}

$\begin{array}{lll}\text { Preface } & \text { IX }\end{array}$

Part I. Language and literacy development

How neuroscience can inform education: A case for prior knowledge

effects on memory

Marlieke T. R. van Kesteren, Dirk J. Ruiter

and Guillén Fernández

The neural basis for primary and acquired language skills

17

Peter Hagoort

Contributions from cognitive neuroscience to current understanding

of reading acquisition and reading disability

Kenneth R. Pugh

Lexical quality revisited

Charles Perfetti

The role of metalinguistic and socio-cognitive factors in reading skill

Hélène Deacon, Rebecca Tucker and Bradley Bergey

Developing reading comprehension interventions: Perspectives

from theory and practice

85

Paul van den Broek, Christine Espin, Kristen McMaster

and Anne Helder

Hunting for the links between word-level writing skills and text quality

103

Naymé Salas and Liliana Tolchinsky

The development of Hebrew conjunct constructions in narration

Dorit Ravid and Liat Hershkovitz 

The paper used in this publication meets the minimum requirements of
the American National Standard for Information Sciences - Permanence
of Paper for Printed Library Materials, ANSI z39.48-1984.

DOI $10.1075 /$ z.206

Cataloging-in-Publication Data available from Library of Congress: LCCN 2017028719 (PRINT) / 2017043994 (E-BOOK)

ISBN 9789027212436 (нB)

ISBN 9789027265159 (Е-BOOK)

(c) 2017 - John Benjamins B.V.

No part of this book may be reproduced in any form, by print, photoprint, microfilm, or any other means, without written permission from the publisher.

John Benjamins Publishing Company $\cdot$ https://benjamins.com 
The role of metalinguistic and socio-cognitive factors in reading skill.

\author{
S. Hélène Deacon, D.Phil. ${ }^{1}$ \\ Rebecca Tucker, B.A. ${ }^{1}$ \\ Bradley Bergey, Ph.D. ${ }^{2}$ \\ ${ }^{1}$ Department of Psychology and Neuroscience \\ Dalhousie University \\ ${ }^{2}$ Department of Secondary Education and Youth Services \\ Queens College, City University of New York
}




\begin{abstract}
.
We present here a review of recent research on the role of metalinguistic and socio-cognitive factors in reading skill. We first review research how morphological awareness and orthographic processing impact the acquisition of reading skill. We show that the first might account for change over time, and the second may not. We then turn to our new studies examining the interplay between these two factors in reading development. In each of these domains, we test predictions of theories of reading development. Finally, we turn to research on a very different set of variables, which we term socio-cognitive. We explore the factors that support academic outcomes for university students with a history of reading difficulties, including the role of a range of coping strategies and support services. Together, we hope that this review inspires new inquiry into understanding the factors that underlie successful reading acquisition.
\end{abstract}

Key words: morphology, orthography, students with a history of reading difficulties

We review here recent research on the role of metalinguistic and socio-cognitive factors in reading skill. This is a joint effort with two young researchers, and we focus primarily, though not exclusively, on research from our lab. Together, we describe collaborative research that has allowed us to explore learning across various domains and developmental stages. 


\section{The role of morphological awareness in children's reading development.}

Morphemes are the fundamental units of meaning in language; they are the building blocks through which words are created in a language. For example, the word magician is made up of two morphemes: the base magic and the suffix -ian. Morphological awareness is the awareness of and ability to manipulate morphemes in oral language. In English, as in many other orthographies, morphemes are represented in print; this explains the use of $c$ rather than $s h$ to spell the word magician (i.e., $c$ from the base magic). As such, children's morphological awareness should determine, at least in part, their progress in learning to read. Our research, along with that of others, has made substantial headway in elucidating the relation between morphological awareness and reading development.

Our ongoing research demonstrates that the relation between children's morphological awareness and their reading skill is independent of multiple other factors, such as phonological awareness and verbal and non-verbal ability (Deacon \& Kirby, 2004; Deacon, 2012; Deacon, Kirby, \& Bell-Casselman, 2009; Kirby et al., 2012; Roman, Kirby, Parrila, Wade-Woolley, \& Deacon, 2009). New research moves beyond correlations at a single time point to evaluate the direction of the relation between two variables. As an example, recent studies demonstrate a bidirectional relation: children's early morphological awareness underpins their progress in learning to read, and children also heighten their morphological awareness through their reading. (e.g., Kruk \& Bergman, 2012; Deacon, Benere, \& Pasquerella, 2013; Deacon, Kieffer, \& Laroche, 2014). The majority of this evidence is in English-monolingual speakers, but there is also evidence of similar relations in Chinese first language speakers (Wu et al., 2009). 
Another key question lies in identifying the mechanisms underlying the relation between morphological awareness and reading comprehension (Deacon \& Kirby, 2004). Given that morphological awareness is a skill in the oral domain, it is important to know just how it connects to reading comprehension — which is making sense of print. The importance of the mechanistic knowledge is made abundantly clear by referring to phonological awareness. There is widespread evidence of the link between phonological awareness and word reading (e.g., Ehri, Nunes, Stahl, \& Willows, 2001). Most importantly, there is good empirical data for the mechanism by which this influence occurs: through the ability to link individual sounds to individual letters (Lyon, Shaywitz, \& Shaywitz, 2003), which supports decoding skill (Vellutino, Fletcher, Snowling, \& Scanlon, 2004) and, in turn, understanding of whole texts (Perfetti, 1985). This mechanistic understanding has provided the basis for sound theory development (e.g., Ehri, 1995), as well as current best practices in early identification and effective remediation (e.g., Ehri et al., 2001; Hammill, \& Newcomer, 1996; Snow et al., 1998). As such, it would be useful to have comparable information as to the mechanisms through which morphological awareness impacts reading comprehension, and our work represents beginning efforts in this direction.

Our recent work explores two variables in particular that are strong candidates as to mechanisms underlying the relation between morphological awareness and reading comprehension. These are morphological decoding and morphological analysis, or the use of morphemes in reading and in understanding words, respectively. In terms of morphological decoding, our work and that of others has demonstrated that middle to upper elementary school aged children use morphemes in their reading of words (e.g., Deacon, 2008; Deacon, Whalen, \& Kirby, 2011; Carlisle, 2000). For example, children are faster and more accurate in reading words of low surface frequency when these have high-frequency than low-frequency bases (e.g., 
comparing locally to avidly). Similarly, in terms of morphological analysis, our newer research demonstrates that children were more accurate in choosing definitions for low frequency derived words when these had high frequency bases than when they had low frequency bases (Deacon, Tong \& Francis, 2015; e.g., contrasting narrowly to cowardly). Morphological decoding and morphological analysis are two skills that might underlie the relation between morphological awareness and reading comprehension.

We are currently testing whether morphological decoding and/or morphological analysis underlies the relation between morphological awareness and reading comprehension. In our first such effort, we conducted a study of 100 children in Grades 3 and 5 (Deacon, Tong, \& Francis, 2015). In linear regression analyses, we found that morphological decoding and morphological analysis each made unique contributions to reading comprehension, beyond controls for children's age, phonological awareness, morphological awareness, nonverbal reasoning, and word reading skill. Given that these relations survived the control for morphological awareness, these findings suggest that each of these two skills might mediate, in part or in full, the relation between morphological awareness and reading comprehension.

In a follow-up study with 200 children in grade 3, we are using mediation models that test more precisely for the possibility of these mediated relations. Here we are contrasting the role of our two morphology-specific tasks, morphological decoding and analysis, with word reading and vocabulary more generally. The preliminary results of this study are intriguing (Levesque, Deacon, \& Kieffer, 2015). Using structural equation modeling, we find that the relation between morphological awareness and reading comprehension is mediated by morphological analysis and decoding, and not by either word reading or vocabulary. These findings demonstrate the very specific link between children's awareness of morphemes in oral language, and their use of 
morphemes in reading and understanding words; these two very specific skills, in turn, contribute to children's understanding of texts. It will be of interest to see which of these variables contribute to gains in reading comprehension, as we follow these children through their development. This program of research will provide comprehensive knowledge of the mechanisms by which morphological awareness contributes to reading comprehension.

\section{Practical implications.}

Our research is motivated in part by the educational importance of identifying mechanisms that underlie reading comprehension. As noted earlier, identified mediators offer great candidates for intervention. As an example, if morphological analysis partially or entirely mediates the relation between morphological awareness and reading comprehension, then it seems that children might benefit from being taught to manipulate morphemes in the oral language and to consider the way in which these morphemes contribute to the meaning of words. Determining the degree of mediation allows educators to make informed decisions as to the relative weighting to be placed on these two skills in the classroom. This question of clarifying the nature of the optimal way to teach children about morphology is a key one that is revisited time and again in reviews and meta-analyses (e.g., Carlisle, 2010; Goodwin \& Ahn, 2010; Reed, 2008; Bowers, Kirby \& Deacon, 2010) and it is one that needs an empirical answer. Together with colleagues, we am also conducting empirical research into the effectiveness of morphological interventions designed to target these key components (Horne-Robinson \& Deacon, 2015). Intervention designs are also important for scientific reasons because they are a key component in demonstrating causality; findings that teaching morphological awareness improves children's 
reading skill would provide a key piece of evidence that morphological awareness causes growth in reading skill. Such causal evidence is needed to make a compelling case that morphological awareness should be included in models of reading development.

\section{The role of orthographic processing in children's reading development.}

Orthographic processing has been defined as the "ability to form, store and access orthographic representations" (Stanovich \& West, 1989, pp. 404). Dominant models of reading propose an orthographic dimension in the transition to automatic word reading (e.g., Ehri, 1995; Share, 1995; see also Castles \& Coltheart, 1993). In this line of research, we are investigating measurement of this construct and its relation to reading. In our view, a key distinction is between two aspects of orthographic processing: orthographic knowledge and orthographic learning (Deacon Benere, \& Castles, 2012; Share, 2008a; Castles \& Nation, 2006). Orthographic knowledge is considered to be the store of existing orthographic representations (or crystallised orthographic processing; e.g., Share, 2008b). Orthographic learning is children's ability to form orthographic representations (or fluid orthographic processing).

Our own research and that of others has demonstrated that orthographic knowledge correlates with word reading skill, independently from other known reading-related skills (such as

phonological and morphological awareness; e.g., Stanovich, West, \& Cunningham, 1991; Roman et al., 2009; Deacon, 2012). This research forms a basis for the idea that appreciating that orthographic knowledge is related to word reading, but does not identify the direction of this relation. Several recent studies now suggest that children's early word reading skill determines 
their improvement in performance on orthographic processing across grades 1 to 3 (Deacon, Benere, \& Castles, 2012; Conrad \& Deacon, submitted). Children's early performance on orthographic processing tasks, on the other hand, is not a predictor of growth in reading skill. These findings counter the assumption that orthographic processing skill plays an "independent causal role" (Burt, 2006, p. 401) in the development of skilled word reading.

Our new research has now turned to evaluating the predictive power of children's orthographic learning on their word reading outcomes. In collaborative research, we have now completed a longitudinal study in which we demonstrate that grade 2 and 3 children's skill in learning orthographic forms does indeed predict their gains in word reading skill (Deacon, Marinus, Tims, \& Castles, in preparation). Intriguingly, there is a very small unique contribution of orthographic learning to gains in word reading — on the order of $1 \%$. Certainly, it is possible that the use of an auto-regressor in this design is too stringent; it might actually capture preexisting orthographic learning skill. It will be important to establish whether the unique contribution of orthographic learning to gains in word reading skill remains for younger readers (e.g., Wolter, Self, \& Apel, 2011).

\section{Practical implications}

From this line of research, it seems that orthographic learning, though perhaps not orthographic knowledge, might contribute to children's gains in word reading skill. The findings that the contribution of orthographic learning to word reading development is very small urges caution in jumping to conclusions about the teaching of orthographic learning. Further, it is not clear how one might go about teaching children skill in orthographic learning, specifically, as 
opposed to knowledge; to date, research has captured this as an individual difference between children, without, at least to our knowledge, discussion of just how 'teachable' this skill is. That said, it seems at least plausible that there might be some value in teaching children higher-level phonological decoding skills to tackle more complex letter patterns; such teaching might bootstrap children as they encounter more complex words. This is an important step for new research.

\section{The interaction between morphological and orthographic factors in children's reading development.}

In this section, we highlight a line of research focusing on the intersection between orthographic learning and morphological awareness. This research brings together our prior research on each of these variables in reading development. Specifically, we report on a set of studies designed to evaluate whether orthographic learning occurs across morphologically related words or more generally across words that share orthographic patterns.

Our research is framed by a prominent theory of reading development: the Self-Teaching Hypothesis (Share, 2008b). Share proposed that children build up an orthographic lexicon by creating and storing orthographic representations of novel words they decode during independent reading. We test key predictions of the Self-Teaching Hypothesis in our research.

The first important feature of the Self-Teaching Hypothesis is the proposal that orthographic learning happens on a word specific level (Share 1995). Strictly interpreted, this feature of the theory would suggest that, when children encode the spelling pattern for one word (e.g., miss), 
their learning is only applicable to that specific word and does not get drawn upon when they encounter related words (e.g., missed or missile). We were interested in this prediction, given our own findings, and those of others, that children are quite sensitive to both morphological and orthographic regularities in print.

As such, we were keen to evaluate whether children might transfer their learning of one word to aid their processing of novel related words - a first step in evaluating whether orthographic learning is strictly word-specific as previously suggested (Tucker, Castles, LaRoche \& Deacon, 2016). To do so, we built on the traditional self-teaching paradigm wherein children were asked to read short stories with nonwords embedded in the text, then tested their orthographic learning using an orthographic choice task (see Nation, Angells, \& Castles, 2007; Share, 1999; Wang, Castles, Nickels, \& Nation, 2011). Critically, in a between-subjects design with children in grades 3 and 5, we manipulated the form of the nonword that children learned: a base form (e.g., feep), a morphologically complex form (e.g., feeper), or an orthographically complex form (e.g., feeple).

For all children, we then evaluated their skill in choosing the correct spelling for all of these forms, regardless of the form that they learned. This approach allowed us to evaluate whether children would transfer their knowledge of a previously learned word (e.g., feep) to their processing of novel words (e.g., feeper and feeple). We found that children chose the correct spellings for all forms of the nonwords at levels above chance, regardless of the form of the nonword they had learned. Furthermore, children chose the correct spellings for morphologically related and orthographically related words at similar levels. As such, it seems that children do indeed transfer their learning of an orthographic form to novel words that they encounter. They appear to do so in a manner that draws on orthographic analogies (e.g., Wood, 2002). 
It was surprising that this study did not demonstrate an added advantage for morphology in children's transfer of orthographic learning. This was the conclusion of the one prior study on this question (Pacton, Foulin, Casalis, \& Treiman, 2013). In a study of French-speaking Grade 3 children, the spellings of base forms were more accurately learned in a morphological condition than in a baseline condition. The morphological condition included explicit information about the morphological relationship between words, and a mixture of both base and derived forms (e.g., vensois, vensoisiste) in which the critical final silent letter was pronounced. The baseline condition included only repetitions of the base form. Children were more accurate in choosing the correct spelling for the base nonwords (e.g., choosing vensois from vensois, vensoit, and vensoie) in the morphological condition than in the baseline condition.

Findings from Pacton et al's (2013) study appears to be more in line with the findings that young English- and French-speaking children are aware of morphological relationships and are able to use that knowledge to support their reading and spelling of real words (e.g., Carlisle \& Stone, 2005; Cassar \& Treiman, 1997; Deacon, Whalen, \& Kirby, 2011; Sénéchal, Basque, \& Leclaire, 2006). And yet, key features of this experimental design motivate further empirical inquiry. The stories in Pacton et al. (2013) included explicit information about the morphological relationship, something that is perhaps not ecologically valid to most of children's reading experiences. Further, the children heard the pronunciation of the final silent consonant in the morphological condition; it is possible that this phonological information alone was responsible for the added advantage in the morphological condition. Similarly, there was a greater diversity in the words to which the children were exposed in the morphological than in the baseline condition. We need to carefully consider experimental designs that might disentangle these factors that could affect children's performance. 
The second important feature of the Self-Teaching Hypothesis is that the orthographic learning process relies on successful decoding of the novel words the readers encounter (Share, 2008). Share (1999) investigated the role of phonological decoding when he had children complete a lexical decision task with target nonwords while they were reciting the nonword $D U B B A$ out loud to interfere with any phonological processing of the nonwords as they read them. Share found that children still showed evidence of orthographic learning, although it was to a significantly lower degree than when there was no phonological interference. Notably, this task is a significant departure from the traditional Self-Teaching paradigm wherein children are learning the novel words through reading connected text.

In our study, we tested this feature of Share's hypothesis by examining the role of decoding. We did so by dividing our data into two groups: orthographic choice responses for which children had decoded the corresponding nonword correctly at least once and orthographic choice responses for which children had no successful decoding attempts for the corresponding nonword. We re-ran our analyses for each of these groups to evaluate whether the pattern of learning, and transfer of learning would differ based on decoding accuracy. We found that both orthographic learning and transfer of that learning to novel items occurred even when children were unable to accurately decode the nonwords. Notably, as in Share (1999), accurate decoding did appear to facilitate the orthographic learning process as the level of learning children achieved when they were able to accurately decode the nonwords was significantly higher than it was when they were unable to.

In follow-up studies we plan to continue investigating these important tenets of the SelfTeaching Hypothesis (Share, 1999) with both older-elementary aged children and beginning readers. To further evaluate the item-specificity of learning, we will combine methodologies 
used in the reviewed studies. For example, we will investigate how learning and the transfer of that learning change as we vary the explicitness of the morphological relationships. To further evaluate the necessity of accurate phonological decoding, we will develop an empirical manipulation of the traditional self-teaching paradigm rather than using post hoc methods. For example, we will investigate how learning and the transfer of learning differ as we manipulate how much children can decode within the stories.

This line of research will contribute to our understanding of how morphological awareness affects the generalization of orthographic learning across novel words, adding to our knowledge of the mechanisms that support orthographic learning within the self-teaching paradigm. Practically speaking, understanding how children naturally learn the spelling patterns of new words as they are encountered, and how they capitalize on that learning to scaffold their own future learning, will help to provide better understanding of how to target those processes and support their development.

\section{Socio-cognitive factors affecting the success of university students with a history of reading difficulty}

Beyond our research with children, an additional focus of our research has been on university students who report difficulty with reading acquisition. Ample evidence exists that children who experience difficulty learning to read have persistent reading deficits into adulthood, including difficulties with word reading, spelling, and decoding (Lefly \& Pennington, 1991). And yet, there are success stories - those who are able to cope with their reading difficulties to the point 
that they can gain admission to university. Our focus has been to examine these students' academic difficulties and achievements at university, and the compensation strategies and institutional services that support their success. Our hope is that such knowledge may shed light on variables to target in supporting both children with dyslexia and university students with a history of reading difficulties. As in our research with children, we think that it is key to evaluate multiple factors that could affect outcomes. In our research with adults with a history of reading difficulties, we work from the assumption that the cognitive difficulties that underlie early reading difficulties interact with various psychological, behavioral, and environmental factors in complex ways over time (Parrila \& McGuire, 2014). These interactions may lead adults with a history of reading difficulty to develop quite different coping strategies and require different resources to support their success.

We identify university students with a history of reading difficulty by asking them to selfreport on their early reading difficulties using the Adult Reading History Questionnaire Revised (ARHQ-R; Parrila, Corkett, Kirby, \& Hein, 2003). The ARHQ-R includes questions about the extent to which individuals report difficulty learning to read as elementary school students. Based on responses to these items, we identify students who report moderate to widespread early reading difficulties, a group we refer to as students with a history of reading difficulty. In our research, we typically compare these students to those who reported very little or no difficulty learning to read.

Our work and those of others point to the validity of using the ARHQ-R to identify university students who continue to struggle with reading (Deacon, Cook, \& Parrila, 2012; Deacon, Parrila \& Kirby, 2006; McGonnell, Parrila \& Deacon, 2007; Parrila, Georgiou \& Corkett, 2007). For example, students who self-report early reading difficulties have remarkably 
similar reading skills as students with diagnosed learning disabilities (Deacon et al., 2012). To put these skills in context, both groups had timed reading comprehension and word reading levels four grade levels below those of their peers without any history of reading difficulty; these scores equate to Level 2 on the International Adult Literacy Survey (Strucker, Yamamoto, \& Kirsch, 2005), a level that is below what is needed to fully participate in a knowledge economy. Further, this focus on an individual's history of reading difficulty is aligned with current approaches to identifying learning disabilities like dyslexia. For example, the Diagnostic and Statistical Manual of Mental Disorders (DSM-5; American Psychiatric Association, 2013) has replaced an IQ-achievement discrepancy approach to identifying specific learning disabilities related to reading with a focus on a documented history of reading and academic difficulty.

Our research indicates that university students with a history of reading difficulty constitute a large but generally invisible population that is academically vulnerable. Across multiple years and institutions, we find that over $20 \%$ of respondents to the ARHQ-R report at least moderate difficulty with reading acquisition (Bergey, Laroche, \& Deacon, 2014). Yet in our samples, only a minority—around one-third— report having a diagnosed learning disability. Without a diagnosis, these students do not receive the same attention and support from universities as students with learning disabilities, despite their similar reading abilities. In addition to belowaverage reading abilities, students with a history of reading difficulty report deficits on measures of metacognitive reading, learning and study strategies (Bergey, Deacon, \& Parrila, 2015; Chevalier, Parrila, Richie, \& Deacon, 2015). For example, students with a history of reading difficulty report more trouble with essential academic skills, such as concentrating, managing anxiety, selecting the main idea, and taking exams compared to students with no history of reading difficulty. These difficulties with academic tasks translate into lower academic 
achievement. In their first year, students with a history of reading difficulty have lower GPAs and successfully earn fewer of the credits they attempt compared to students with no history of reading difficulty (Bergey et al; Chevalier et al.). Most troublingly, students with a history of reading difficulty are more likely to drop out after each academic year compared to typical university students (Bergey, Horne-Robinson, Parrila, \& Deacon, submitted). Taken together, these results indicate that students with a history of reading difficulty are academically at-risk and are likely to require additional resources to help them succeed at university.

One of our aims in this line of research has been to identify factors associated with academic achievement for university students with a history of reading difficulty, since these associations may point to how these students can be best supported. One such variable may be the use of academic support services. Students with a history of reading difficulty who use academic support services-for example, talking with academic advisors, seeking writing help from tutors, and attending study skills workshops - are less likely to dropout than their counterparts who do not use these services (Bergey et al., submitted). Further, intrapersonal and interpersonal resources that contribute to resilience may be key in supporting the academic success and well being of these students (Corkett, Hein, \& Parrila, 2008; Stack-Cutler, Parrila, \& Torppa, 2014; Stack-Cutler, Parrila, Jokisaari, \& Nurmi, 2015).

Practical implications and next steps.

Part of our work with this population has involved designing and evaluating low-cost, scalable interventions to support the academic achievement of students with a history of reading difficulty. As a first step, we have tested the effects of providing proactive and personalized 
invitations to students with a history of reading difficultly to meet with academic advisors who can assist them with course and degree selection and can make referrals to other support services (Deacon, Tucker, Bergey, Laroche, \& Parrila, submitted). Students with a history of reading difficulty who received this targeted outreach used academic advising to a greater extent in both their first and second year compared to students with a history of reading difficulty in a matched control condition. Importantly, students with a history of reading difficulty who experienced serious academic difficulties during their first year were far more likely to use academic advising in their second year if they had received outreach in the first year. Thus, this modest approach of identifying students with a history of reading difficulty at the start of university and providing targeted efforts to connect them to advising services appears to be a cost-effective first step in supporting these academically vulnerable students. Research is currently underway to examine whether a reading and study strategy training intervention supports students' development of study skills and academic achievement.

The research base on adults with early reading difficulties is modest, and many questions remain. One set of questions relates to how reading difficulties affect and are compensated in specific post-secondary learning contexts. For example, different academic disciplines (e.g., sciences vs. humanities) make different reading demands on students (Heiman \& Precel, 2003) and are likely to influence the difficulties and compensation strategies students with a history of reading difficulty use. Evidence supporting this hypothesis is found in an intriguing pattern of group differences in academic achievement by faculty. For example, compared to students with no history of reading difficulty, those with a history of reading difficulty earned higher GPAs in professional programs, but dramatically lower GPAs in Arts and Social Sciences (Bergey et al., 2015). Research is also needed to understand the economic outcomes for individuals with a 
history of reading difficulties, and, in particular, the implications of dropping out. These lines of research will extend our understanding of how reading difficulties impact the lives of individuals and how to help those who struggle with reading achieve their academic and personal goals.

\section{Conclusion.}

We hope that our overview inspires further investigation into the role that metalinguistic and socio-cognitive factors play in children's and adults' reading outcomes. We think that one important next step lies in delineating how orthographic and morphological factors interact in reading development. For example, empirical efforts to date have primarily focused on identifying the unique variance associated with each of these factors. This approach has been important in demonstrating that these factors are worth having on the table for discussion. However, the reality for children is that they confront words with many different types of regularities (e.g., phonological, orthographic and morphological) in rich complex texts. And so it seems important for new research to examine how children tackle this complex world of words and ideas, including the overlap and uniqueness between factors. Another important step lies in understanding how it is that university students with a history of reading difficulties overcome reading challenges to the point that they can participate in post-secondary education. Such research needs to acknowledge that this group likely has both strengths and weaknesses. The former are captured in the fact that they have made it to university and the latter are clearly demonstrated in their academic performance once they arrive. Examining the factors that lead to both is key to ensuring that we know how to support these individuals so that they reach their 
academic potential. In each of these areas, we think a multiple-factor approach can move us forward in understanding the complexity of reading and learning experiences. 


\section{References}

American Psychiatric Association. (2013). Diagnostic and statistical manual of mental disorders (5th ed.). Washington, DC: Author.

Bergey, B. W., Deacon, S. H., \& Parrila, R. (2015). The metacognitive reading and study strategies and academic achievement of university students with and without a history of reading difficulty. Journal of Learning Disabilities. Advance online publication. doi:10.1177/0022219415597020

Bergey, B. W., Horne-Robinson, H., Parrila, R. K., Deacon, S. H. (submitted). Academic support service use and academic achievement of university students with a history of reading difficulty: A mixed method study. Manuscript under review for publication.

Bergey, B. W., Laroche, A., \& Deacon, H. (2014, May). The impacts of early challenges in acquiring reading: the learning, reading and organizational skills of university students with a history of reading difficulties. In H. Deacon (Chair), Recent Canadian reading research across educational contexts. Symposium at Canadian Conference on Developmental Psychology; Ottawa, Ontario.

Bowers, P., Kirby, J.R., \& Deacon, S.H. (2010). The effects of morphological instruction on literacy skills: A systematic review of the literature. Review of Educational Research, 80(2), 144-172.

Burt, J. S. (2006). What is orthographic processing skill and how does it relate to word identification in reading? Journal of Research in Reading, 29(4), 400-417.

Carlisle, J. F. (2000). Awareness of the structure and meaning of morphologically complex words: Impact on reading. Reading and Writing, 12, 169-190. 
Carlisle, J. F. (2010). Effects of instruction in morphological awareness on literacy achievement: An integrative review. Reading Research Quarterly, 45(4), 464-487.

Carlisle, J. F., \& Stone, C. (2005). Exploring the role of morphemes in word reading. Reading Research Quarterly, 40(4), 428-449.

Cassar, M., \& Treiman, R. (1997). The beginnings of orthographic knowledge: Children's knowledge of double letters in words. Journal of Educational Psychology, 89, 631-644.

Castles, A., \& Coltheart, M. (1993). Varieties of developmental dyslexia. Cognition, 47(2), 149180.

Castles, A., \& Nation, K. (2006). How does orthographic learning happen? From inkmarks to ideas: Current Issues in Lexical Processing, 151.

Chevalier, T. M., Parrila, R., Ritchie, K. C., \& Deacon, S. H. (2015). The role of metacognitive reading strategies, metacognitive study and learning Strategies, and behavioral study and learning strategies in predicting academic success in students with and without a history of reading difficulties. Journal of Learning Disabilities, doi: 10.1177/0022219415588850

Conrad, N. \& Deacon, S.H. (submitted). Children's orthographic knowledge and their word reading skill: Testing bi-directional relations. Scientific Studies of Reading.

Corkett, J. K., Hein, S. F., \& Parrila, R. (2008). Compensating for reading difficulties: A qualitative investigation of university students' experiences of influential personal characteristics. Exceptionality Education International, 18(2), 51-68.

Deacon, S.H. (2008). The metric matters: Determining the extent of children's knowledge of morphological spelling regularities. Developmental Science, 11(3), 396-406. 
Deacon, S.H. (2012). Sounds, letters, and meanings: The independent influences of phonological, morphological, and orthographic skills on early word reading accuracy. Journal of Research in Reading, 35(4). doi: 10.1111/j.1467-9817.2011.01496.x

Deacon, S.H., Benere, J., \& Castles, A. (2012). Chicken or egg? Untangling the relationship between orthographic processing and reading. Cognition, 122(1), 110-117.

Deacon, S.H., Benere, J., \& Pasquerella, A. (2013). Reciprocal relationship: Children's morphological awareness and their reading accuracy across grade 2 to 3 . Developmental Psychology, 49(6), 1113-1126. doi: 10.1037/a0029474

Deacon, S. H., Cook, K., \& Parrila, R. (2012). Identifying high-functioning dyslexics: Is selfreport of early reading problems enough? Annals of Dyslexia, 62(2), 120-134. doi:10.1007/s11881-012-0068-2

Deacon, S. H., Kieffer, M. J., \& Laroche, A. (2014). The relation between morphological awareness and reading comprehension: Evidence from mediation and longitudinal models. Scientific Studies of Reading, 18(6), 432-451.

Deacon, S.H., \& Kirby, J. (2004). Morphological awareness: Just 'more phonological'? The roles of morphological and phonological awareness in reading development. Applied Psycholinguistics, 25, 223-238.

Deacon, S.H., Kirby, J., \& Bell-Casselman, M. (2009). How robust is the contribution of morphological awareness to spelling? Reading Psychology, 30(4), 301-318.

Deacon, S.H., Marinus, E., Tims, T., Castles, A. (in preparation). How children's orthographic learning predicts their word reading development.

Deacon, S. H., Parrila, R., \& Kirby, J. R. (2006). Processing of derived forms in high-functioning dyslexics. Annals of Dyslexia, 56(1), 103-128. 
Deacon, S. H., Tong, X., \& Francis, K. (2015). The relationship of morphological analysis and morphological decoding to reading comprehension. Journal of Research in Reading. Advance online publication. doi:10.1111/1467-9817.12056

Deacon, S. H., Tucker, R., Bergey, B. W., Laroche, A., \& Parrila, R. (submitted). Outreach to university students with a history of reading difficulties: Early screening and outreach to support academically at-risk students. Manuscript under review.

Deacon, S.H., Whalen, R., \& Kirby, J.R. (2011). Do children see the danger in dangerous? Grade 4, 6 and 8 children's reading of morphologically complex words. Applied Psycholinguistics, 32 (3), 467-481.

Ehri, L. C. (1995). Phases of development in learning to read words by sight. Journal of research in Reading, 18(2), 116-125.

Ehri, L. C., Nunes, S. R., Stahl, S. A., \& Willows, D. M. (2001). Systematic phonics instruction helps students learn to read: Evidence from the National Reading Panel's meta-analysis. Review of Educational Research, 71(3), 393-447.

Goodwin, A. P., \& Ahn, S. (2010). A meta-analysis of morphological interventions: Effects on literacy achievement of children with literacy difficulties. Annals of Dyslexia, 60(2), 183208.

Heiman, T., \& Precel, K. (2003). Students with learning disabilities in higher education: Academic strategies profile. Journal of Learning Disabilities, 36(3), 248-258.

Horne-Robinson, H., \& Deacon, S.H. (2015, April). Wordology! Words as building blocks. Poster presented at the Nova Scotia Developmental Psychology Conference, Wolfville, Nova Scotia, Canada. 
Kirby, J.R., Deacon, S.H., Bowers, P.N., Izenberg, L., Wade-Woolley, L., \& Parilla, R. (2012). Children's morphological awareness and reading ability. Reading \& Writing: An Interdisciplinary Journal, 25(2), 389-410.

Kruk, R. S., \& Bergman, K. (2013). The reciprocal relations between morphological processes and reading. Journal of Experimental Child Psychology, 114(1), 10-34.

Lefly, D. L., \& Pennington, B. F. (1991). Spelling errors and reading fluency in compensated adult dyslexics. Annals of Dyslexia, 41(1), 141-162.

Levesque, K., Deacon, S. H., \& Kieffer, M. J. (2015, July). Direct and indirect morphological contributions to children's reading comprehension: A multiple mediation approach. Paper presented at the 22nd annual meeting of the Society for the Scientific Study of Reading, Hawaii, USA

Lyon, G. R., Shaywitz, S. E., \& Shaywitz, B. A. (2003). A definition of dyslexia. Annals of Dyslexia, 53(1), 1-14.

McGonnell, M., Parrila, R., \& Deacon, S. H. (2007). The recruitment and description of university students who self-report difficulty acquiring early reading skills. Exceptionality Education Canada, 17(1/2), 155.

Nation, K., Angells, P., \& Castles, A. (2007). Orthographic learning via self-teaching in children learning to read English: Effects of exposure, durability, and context. Journal of Experimental Child Psychology, 96(1), 71-84. doi:10.1016/j.jecp.2006.06.004

Pacton, S., Foulin, J.N., Casalis, S., \& Treiman, R. (2013). Children benefit from morphological relatedness when they learn to spell new words. Frontiers in Psychology, 4 (696), 1-7. doi: 10.3389.psyg.2013.00696. 
Parrila, R., Corkett, J., Kirby, J., \& Hein, S. (2003). Adult Reading History QuestionnaireRevised. Unpublished questionnaire, University of Alberta, Edmonton, Canada.

Parrila, R., Georgiou, G., \& Corkett, J. (2007). University students with a significant history of reading difficulties: What is and is not compensated? Exceptionality Education Canada, $17(2), 195-220$.

Parrila, R., \& McQuarrie, L. (2014). Cognitive processes and academic achievement: Multiple systems model of academic achievement. In T. C. Papadopoulos, R. Parrila, \& J. R. Kirby (Eds.), Cognition, intelligence, and achievement: A tribute to J. P. Das (pp. 79100). San Diego, CA: Elsevier.

Perfetti, C. A. (1985). Reading ability. New York, New York: Oxford University Press.

Reed, D. K. (2008). A synthesis of morphology interventions and effects on reading outcomes for students in grades K-12. Learning Disabilities Research \& Practice, 23(1), 36-49.

Roman, A., Kirby, J., Parrila, R., Wade-Woolley, L., \& Deacon, S.H. (2009). Towards a comprehensive view of the skills involved in word reading in Grades 4, 6, and 8. Journal of Experimental Child Psychology, 102(1), 96-113.

Sénéchal, M., Basque, M. T., \& Leclaire, T. (2006). Morphological knowledge as revealed in children's spelling accuracy and reports of spelling strategies. Journal of Experimental Child Psychology, 95(4), 231-254. doi:10.1016/j.jecp.2006.05.003

Share, D.L. (1995). Phonological recoding and self-teaching: Sine qua non of reading acquisition. Cognition, 55, 151-218.

Share, D. L. (1999). Phonological recoding and orthographic learning: A direct test of the selfteaching hypothesis. Journal of Experimental Child Psychology, 72(2), 95-129. doi:10.1006/jecp.1998.2481 
Share, D.L. (2008a). On the anglocentricities of current reading research and practice: The perils of overreliance on an "Outlier" orthography. Psychological Bulletin, 134, 4, 584-615. doi: $10.1037 / 0033-2909.134 .4 .584$

Share, D. L. (2008b). Orthographic learning, phonological recoding, and self-teaching. In R. V. Kail (Ed.), Advances in child development and behavior (Vol 36) (pp. 31-82). San Diego, CA US: Elsevier Academic Press. doi:10.1016/S0065-2407(08)00002-5

Stack-Cutler, H. L., Parrila, R. K., Jokisaari, M., \& Nurmi, J.-E. (2015). How university students with reading difficulties are supported in achieving their goals. Journal of Learning Disabilities, 48(3), 323-334. doi:10.1177/0022219413505773

Stack-Cutler, H. L., Parrila, R. K., \& Torppa, M. (2014). Using a multidimensional measure of resilience to explain life satisfaction and academic achievement of adults with reading difficulties. Journal of Learning Disabilities, 1-12. doi:10.1177/0022219414522705

Stanovich, K. E., \& West, R. F. (1989). Exposure to print and orthographic processing. Reading Research Quarterly, 21, 360-407.

Stanovich, K.E., West, R.F., \& Cunningham, A.E. (1991). Beyond phonological processes: Print exposure and orthographic processing. In S.A. Brady \& D.P. Shankweiler (Eds.), Phonological processes in literacy: A tribute to Isabelle Y. Liberman (pp. 219-235). Hillsdale, NJ, England: Lawrence Erlbaum Associates, Inc.

Strucker, J., Yamamoto, K., \& Kirsch, I. (2005). The relationship of the component skills of reading to performance on the International Adult Literacy Survey (IALS). A NCSALL Research Brief. Retrieved from $\underline{\text { http://www.ncsall.net/fileadmin/resources/research/reading_ials_rb.pdf }}$ 
Tucker, R., Castles, A., Laroche, A., \& Deacon, S. H. (2016). The nature of orthographic learning in self-teaching: Testing the extent of transfer. Journal of Experimental Child Psychology, 145, 79-94. doi: 10.1016/j.jecp.2015.12.007

Vellutino, F. R., Fletcher, J. M., Snowling, M. J., \& Scanlon, D. M. (2004). Specific reading disability (dyslexia): What have we learned in the past four decades? Journal of child psychology and psychiatry, 45(1), 2-40.

Wang, H., Castles, A., Nickels, L., \& Nation, K. (2011). Context effects on orthographic learning of regular and irregular words. Journal of Experimental Child Psychology, 109(1), 39-57. doi:10.1016/j.jecp.2010.11.005

Wolter, J. A., Self, T., \& Apel, K. (2011). Initial mental graphemic representation acquisition and later literacy achievement in children with language impairment: A longitudinal study. Journal of Learning Disabilities, 44, 543-555. doi:10.1177/0022219410392042

Wood, C. (2002). Orthographic analogies and phonological priming effects. Journal of Research in Reading, 25(2), 144-159. doi:10.1111/1467-9817.00165

Wu, X., Anderson, R.C., Li., W., Wu, X., Li, H., Zhang, J., Zheng, Q., Zhu, J., Shu, H., Jiang, W., Chen, X., Wang, Q., Yin, L., He, Y., Packard, J., \& Gaffney, J.S. (2009). Morphological awareness and Chinese children's literacy development: An intervention study. Scientific Studies of Reading, 13, 26-52. doi:10.1080/10888430802631734 